\title{
Green and chemical synthesis of zinc oxide nanoparticles and size evaluation by UV-vis spectroscopy
}

\begin{abstract}
Development of green chemistry in the synthesis of nanoparticles with the use of plants is a cost-effective and eco-friendly approach. In this research, we described the one pot green synthesis of Zinc oxide nanoparticles (ZnO-NPs) using aqueous extracts of Origanum majorana, Ziziphus jujuba (Z. jujuba), Elaeagnus angustifolia fresh leaves, Cucumber fruit and Pomegranate peel, and then size of nanoparticles was compared with chemical synthesized $\mathrm{ZnO}$ nanoparticles. The average sample crystal size was calculated by X-ray diffraction (XRD) using Debye-Scherrer equation. Scanning electron microscope (SEM) micrographs showed the spherical shape of ZnO-NPs. Functional groups determined by Fourier transform infrared spectroscopy (FTIR) and the presented simple approach described that there is the relationship between the optical absorption spectrum of $\mathrm{ZnO}$ nanoparticles caused by surface plasmon absorption (in particular, the plasmon resonance and its broadening) and their sizes.
\end{abstract}

Keywords: Origanum majorana, Ziziphus jujube, Elaeagnus angustifolia, Cucumber, Pomegranate, $\mathrm{ZnO}-\mathrm{NPs}$
Research Article

Volume 7 Issue I - 2018

\author{
Melika Mohammadian, Zarrin Es'haghi, Sara \\ Hooshmand \\ Department of Chemistry, Payame Noor University, Iran
}

Correspondence: Zarrin Es'haghi, Department of Chemistry, Payame Noor University, 19395-4697, Tehran, Iran, Email eshaghi@pnu.ac.ir

Received: January 19, 2018 | Published: February 23, 2018

\section{Introduction}

Extremely small nanomaterials with dimensions roughly less than 100 nanometers $(\mathrm{nm})$, can demonstrate atom-like behaviors resulting from higher surface energy because of their large surface area and broad band gap between valence and conduction band when nanomaterials are divided into near atomic size. ${ }^{1} \mathrm{ZnO}$ nanopowders are basic metal oxide particles with interesting properties and wide applications in several fields. We chose $\mathrm{ZnO}-\mathrm{NPs}$ as they are promising candidates for various applications such as chemical sensors, ${ }^{2}$ nano generators, ${ }^{3}$ catalysis, ${ }^{4}$ anti-microbial and anti-corrosive ${ }^{5}$ and piezoelectric devices. ${ }^{6} \mathrm{ZnO}$ nanoparticles, based on its unique properties such as: low toxicity, high selectivity and biocompatibility, have shown that they are inherently selective cytotoxicity against carcinogenic cells compared with other nanoparticles. Therefore, they can be regarded as a promising anti-cancer agent. Zinc, as the co-factor of more than hundreds of enzymes, plays an important role in cellular processes, including: DNA replication, DNA repair, cell cycle progression and it has the exclusive ability to induce oxidative stress in cancer cells, as one of the mechanisms of its cytotoxicity towards tumor cells. Thus, the potential use of nano $\mathrm{ZnO}$ in biomedicine is important in the medical societies. ${ }^{7} \mathrm{ZnO}$ nanomaterials possesses exclusive semiconducting, optical, and piezoelectric properties hence has been examined for biomedicine applications, such as biomedical imaging includes fluorescence, magnetic resonance, tomography, drug delivery, and biosensing of a wide range of molecules. ${ }^{8} \mathrm{ZnO}$ due to a wide band gap semiconductor and high exciton binding energy is an efficient excitonic blue and near-UV emitter so, owing to its stability and inherent capability to absorb UV irradiation, $\mathrm{ZnO}$ nanoparticles widely used in sunscreens. ${ }^{8}$ According to the literatures, many other different synthesis methods have been developed for
$\mathrm{ZnO}$ nanoparticles including mechanochemical processing and selfassembling, ${ }^{9}$ microwave method, ${ }^{10}$ direct precipitation, ${ }^{11}$ reversed micelle, ${ }^{12}$ RF plasma synthesis. ${ }^{13}$ Usually these methods have disadvantages, such as, they do not have a uniform distribution of particle size or particle size is coarse. To resolve this problem, according to a new research which was offered on the basis of colloid chemistry, there was a surface coating surrounding the particles. In these processes, some materials added to the solution, which affects the surface tension and prevents it from agglomeration. Plant extracts contain factors that inhibit the aggregation of particles and result in produced smaller-sized particles. The use of plants for synthesis of nanoparticles due to the use of a nontoxic agent is one of the environmentally friendly methods. Green synthesis of $\mathrm{ZnO}-\mathrm{NPs}$ is an increasingly interesting topic.

Chemical methods need to use of toxic chemical solvents such as reducing agents and these methods are expensive. Recently in nanotechnology, scientists wish for green synthesis with plant extracts, because this method has been useful and plays a very important role which is cheap, clean, safe, eco-friendly, non-toxic and without any dangerous substance. Nanoparticles have many methodical applications and new properties in different fields of medicine, cosmetics, drug-delivery systems, DNA labeling, sensors, catalysis and so on. In the green synthesis of nanoparticles, the phytoconstituents are the responsibility to reduce the size of nanoparticles, such as proteins, phenols, carbohydrates, flavonoids, alkaloids and amino acids. ${ }^{14} \mathrm{We}$ use plants and fruits that have properties natural antioxidants, for absorbing radicals, these compounds have the main role to absorb and neutralize and this property confirmed by articles. ${ }^{15}$ Nanomaterials are ports between bulk materials and very small structures such as atoms or molecules. Because of their small size, they have a large surface 
area to volume ratio. Origanum majorana L. (Family-Lamiaceae) has been used in regional cooking for centuries. It is well-recognized with its famous name sweet marjoram. Majorana is used fresh or dried and give a sweet, spicy, almost piney taste that compliments meats, sauces, vegetables and a rich source of polyphenols, they are natural antioxidants. ${ }^{16}$ Sweet marjoram has surface roots, stemmed branches up to $60 \mathrm{~cm}$ long and covered with gray hairs. Majorana heap shaping plant has upright, hairy, gray-green leaves. ${ }^{17}$ Green synthesis of $\mathrm{ZnO}-$ NPs was done using Origanum majorana leaves extract with decoction method for extraction. It has hydroquinone, sitosterol, flavonoids, tannins, cis-sabinene hydrate, phenolic terpenoids, triacontan and phenolic glycosides. ${ }^{18}$ Sweet marjoram was used by the old Greeks as a cure for several ailments including convulsions, dropsy and poisons. Today herbal tea usage is treating nervous disorders and boredom, depression, epilepsy, headaches, indigestion, flatulence, colic in children, nausea, relieving the pain of childbirth, cough, and cold. Marjoram is antiviral, bactericidal, antiseptic and antifungal. ${ }^{19}$ Origanum majorana appeared to be a strong deterrent in Alzheimer's disease. ${ }^{20} Z$. jujuba belongs to the family of Rhamnaceae. This plant is found about everywhere. The leaves are used for permeability enhancement activity, antipyretic and treatment typhoid fever, antiinflammatory, emollient, expectorant, hair growth, antitumor, pimple, anticancer, soothing, anti-sweet, blood purifier, antimicrobial, therapy of diarrhoea and obesity. ${ }^{21}$ Phytochemical studies on the leaves of $Z$. jujuba and reported to have several saponin glycosides, alkaloids, flavonoids, steroids, polysaccharides and terterpenic acids. ${ }^{22}$

Elaeagnus angustifolia from the Elaeagnaceae family, generally known as oleaster or senjed (in Iran) is used as a food component or herbal remedy for its famous medicinal properties. Elaeagnus angustifolia is a generally hispid shrub or short tree growing to 5-12 meters in height. Its stems, buds and leaves have a thick coating of silvery to rusty scales. The leaves are alternate, sharp, 4-9 $\mathrm{cm}$ long and $1-2.5 \mathrm{~cm}$ wide with a smooth margin. ${ }^{23}$ Flower, fruit, leaf and bark Elaeagnus angustifolia are used for treatment of asthenia of the spleen and stomach ${ }^{24}$ anti-diarrheal, heap to protective and treatment of gastric pain, ${ }^{25}$ cough and cold remedies, ${ }^{26}$ hair tonic for long and shiny hairs, ${ }^{27}$ sore throat and high fever and asthma treatment, ${ }^{28}$ bronchial and lung diseases. ${ }^{29}$ Elaeagnus angustifolia contains Amino acid, $\beta$-carboline alkaloid, Carbohydrate, Cardiac glycoside, Flavonoid, Phenol, Pyrimidine and Vitamins..$^{30}$ In this study, we report a rapid, cost-effective, simple and environmentally method for biosynthesis of zinc oxide nanoparticles using Elaeagnus angustifolia leaves to extract as the capping and stabilizing agent. Most of Cucumber fruit is water, more than $96 \%$. Other compounds in Cucumber such as vitamins, minerals, steroids, amino acids, flavonoids phytosterols, phenolic acids, carbohydrates and fatty acids. Extract of cucumber is rich in vitamins such as vitamin $\mathrm{C}$ and $\mathrm{A}$, these vitamins are important for skin beauty. Cucumber has a high potential in cosmetics for example healing and soothing to an irritated skin and other using of Cucumber extract is for skin problems, sunburn, wrinkles. ${ }^{31}$

Pomegranate tree grows between five and eight meters tall, and is a deciduous shrub with small leaves. The peel of the fruit pomegranate is used as a traditional remedy treatment for diarrhea, dysentery and intestinal parasites. Major chemical compounds of pomegranate aqueous peel extract are punicalagin, punicalin, ellagic acid, gallic acid, quercetin, luteolin, kaempferol and naringennin. ${ }^{32}$ In the present study, we report the synthesis of $\mathrm{ZnO}$ nanoparticles by using green and chemical methods then determined and compared the size of the ZnO-NPs with FTIR, XRD, UV-Vis and SEM. Comparison of the nanoparticle size from Debye-Scherrer equation, Brus equation, and SEM was carried out. By using maximum wavelength $\lambda_{\max }$ from UVVis spectra, energy gap $\left(E_{\mathrm{g}}\right)$ for nanoparticles calculated and the size of nanoparticles studied via Brus equation. In green methods, a decrease in nanoparticle size toward chemical method was observed that can be proved according to the blue shift obtained from $\mathrm{ZnO}$ nanoparticle UV-Vis spectra. Nanometer-sized particles are of real current interest because of their special size-dependent physical properties. DebyeScherrer diffraction patterns are often used to characterize samples, as well as to probe the structure of nanoparticles. But, the well-known Scherrer formula is unreliable at estimating particle size, because assume an underlying crystal structure is often invalid. A simple approach is presented here which takes the UV-Vis spectra of the nanoparticles. There is the relationship between the optical absorption spectrum of nanoparticles caused by surface plasmon absorption and their sizes. Such absorption spectra can be analyzed using the Brus equation.

\section{Experimental}

\section{Preparation of leaves extract}

Origanum majorana plant was prepared from Iran, Khorasan Razavi, Mashhad. The leaves were washed repeatedly with distilled and de-ionized water to clear dust particles and then dried in open air. We put $20 \mathrm{~g}$ of finely powdered leaves in $600 \mathrm{~mL}$ glass beaker with $250 \mathrm{~mL}$ of de-ionized water. The mixture was put in heater at $50^{\circ} \mathrm{C}$ for $30 \mathrm{~min}$ to complete the reaction. The extract was cooled at room temperature and filtered. Finally, the extract was stored at $15^{\circ} \mathrm{C}$ to use for further studies..$^{33}$ These processes were repeated to get the other extracts.

\section{Preparation of ZnO-NPs}

We used four methods for green synthesis of nanoparticles, first method using Zinc nitrate and drying in the oven, the second method is the addition of Zinc nitrate on to the large volumes of plant extracts to saturate the surface of the nanoparticles and drying in the oven and this method repeated again for Zinc acetate, the third method drying on heater for a long time and fourth method which was validated using Zinc acetate and adding a few amount of extracts then dried in vacuum oven. $\mathrm{ZnO}-\mathrm{NPs}$ were prepared by green and chemical methods (Figure 1) which show green synthesis method. In this method, $20 \mathrm{~g}$ of zinc acetate dihydrate $\mathrm{Zn}\left(\mathrm{CH}_{3} \mathrm{COO}\right)_{2} \cdot 2 \mathrm{H}_{2} \mathrm{O}$ was added to $50 \mathrm{~mL}$ of de-ionized water under constant stirring for $30 \mathrm{~min}$ to start the process, then $5 \mathrm{~mL}$ of aqueous extract was added into the solution. In order to adjust $\mathrm{pH}$ solution to 12 , sodium hydroxide $(\mathrm{NaOH}) 2 \mathrm{M}$ was added drop-wise while stirring. With continuous stirring at room temperature for 2 hours. The precipitate was separated by centrifugation at $2000 \mathrm{rpm}$ for $10 \mathrm{~min}$. Finally, obtained fine precipitate was washed twice with de-ionized water and then with ethanol to remove unreacted materials and impurities. After drying the product at $60^{\circ} \mathrm{C}$ in vacuum oven for $12 \mathrm{~h}$. This synthesis is repeat for other extracts to earn nanoparticles in several size and we get powders in deferent colors. Different colors show different size of nanoparticles. Figure 1 also shows chemical method that 20 g Zinc acetate dissolved into glass breaker with $50 \mathrm{~mL}$ de-ionized 
water and the solvent was under constant stirring. Adding aqueous $\mathrm{NaOH}$ solution $(2 \mathrm{M})$ drop-wise at room temperature to increased $\mathrm{pH}$ of the solution to 12 then stirring for 2 hours. The white precipitate was washed with de-ionized water and ethanol to remove all the ions, impurities and unreacted compounds then centrifuged at $2000 \mathrm{rpm}$ for $10 \mathrm{~min}$. Precipitate drying in the vacuum oven for $12 \mathrm{~h}$ at $60^{\circ} \mathrm{C}$, in this stage $\mathrm{ZnO}-\mathrm{NPs}$ production from $\mathrm{Zn}(\mathrm{OH})_{2}$ [34]. The basic chemical reaction governing the formation of $\mathrm{ZnO}$ is as follows:

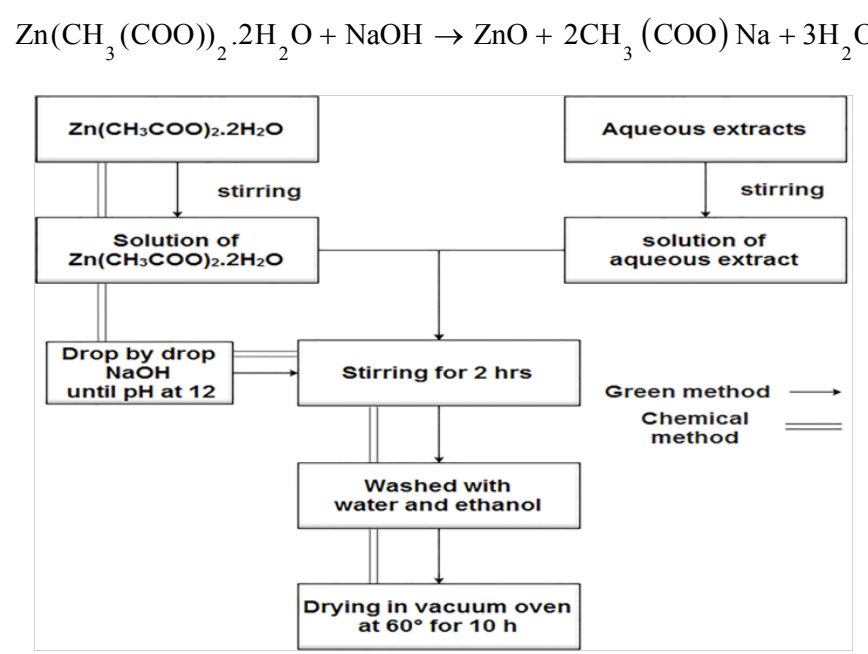

Figure I Preparation of ZnO-NPs with chemical and green methods.

\section{Results and Discussion}

\section{FTIR analysis}

FTIR analysis was performed to find the functional groups on aqueous extract of plants and identify their role in the synthesis of ZnO-NPs. The samples synthesized by the green method and chemical method were analyzed by FTIR. The absorption peaks in Figure 2A shows green method with Origanum majorana extracts were at $3385,2919,2360,1664,1512,1369,1085,1035,906,748,622$ and $424 \mathrm{~cm}^{-1}$. Figure 2A shows FTIR spectra of ZnO-NPs prepared by aqueous extract by Origanum majorana. The absorption peak at 424 $\mathrm{cm}^{-1}$ indicates exist ZnO-NPs. ${ }^{35} \mathrm{~A}$ wide absorption peak at $3385 \mathrm{~cm}^{-1}$ corresponds to $-\mathrm{OH}$ stretching vibrations of water molecules. The $2360 \mathrm{~cm}^{-1}$ band is due to $\mathrm{N}-\mathrm{H}$ stretching. The FTIR spectra shows the exits bonds due to aldehydes C-H stretching about $2919 \mathrm{~cm}^{-1} \cdot{ }^{36}$ The peaks at 1664 and $1512 \mathrm{~cm}^{-1}$ are due to the amide I and amide II that are special regions for proteins. ${ }^{37}$ The peaks at $1369 \mathrm{~cm}^{-1}$ is related to $\mathrm{C}-\mathrm{N}$ stretching and 1035 and $1085 \mathrm{~cm}^{-1}$ stretching vibration absorption peak of $\mathrm{C}-\mathrm{O}$ and $\mathrm{C}-\mathrm{O}-\mathrm{C}{ }^{38}$ The pattern of absorption at $500-1000 \mathrm{~cm}^{-1}$ is responsible to the different modes of $\mathrm{CO}_{2}^{-2}$ caused from the collision of carboxylic groups in protein of extract or unreacted acetate. ${ }^{39}$ The structural changes in FTIR spectra presents the cover and stabilization of $\mathrm{ZnO}-\mathrm{NPs}$ via the coordination with $\mathrm{OH},-\mathrm{NH}, \mathrm{C}-\mathrm{N}$ and aldehydes. In Figure 2A shows biomolecules in aqueous leaf extract of the $Z$. jujuba aqueous extract are important factors in reducing the size and stability of the nanoparticles and prevent clotting. The absorption peaks with $Z$. jujuba were at 3390 , 2931, 2084, 1726, 1577, 1469, 1411, 1282, 1178, 1053, 953, 925, 788, 639 and $455 \mathrm{~cm}^{-1}$. The FTIR spectrum of $\mathrm{ZnO}-\mathrm{NPs}$ prepared by Z. jujube extract in Figure 2A the broad band at $3390 \mathrm{~cm}^{-1}$ corresponds to stretching vibrations of water molecules. The 2931 and the weak absorption at $2084 \mathrm{~cm}^{-1}$ are due to $\mathrm{C}-\mathrm{H}$ stretching of alkanes and $\mathrm{C} \equiv$ $\mathrm{C}$ stretching vibration. The peaks at 1577 and $1726 \mathrm{~cm}^{-1}$ indicated the amide I, II. Absorption in 1411 and $1469 \mathrm{~cm}^{-1}$ often points an aromatic ring. The peaks at $1282 \mathrm{~cm}^{-1}$ are relevant to $\mathrm{C}-\mathrm{N}$ stretching also the peak at 1178 and $1053 \mathrm{~cm}^{-1}$ stretching vibration absorption peak of $\mathrm{C}-\mathrm{O}$ and $\mathrm{C}-\mathrm{O}-\mathrm{C}$. The schema of absorption at $500-1000 \mathrm{~cm}^{-1}$ is related to the different modes of $\mathrm{CO}_{2}^{-2}$. The absorption peak at 455 $\mathrm{cm}^{-1}$ indicates the attendance of $\mathrm{ZnO}$ nanoparticle.

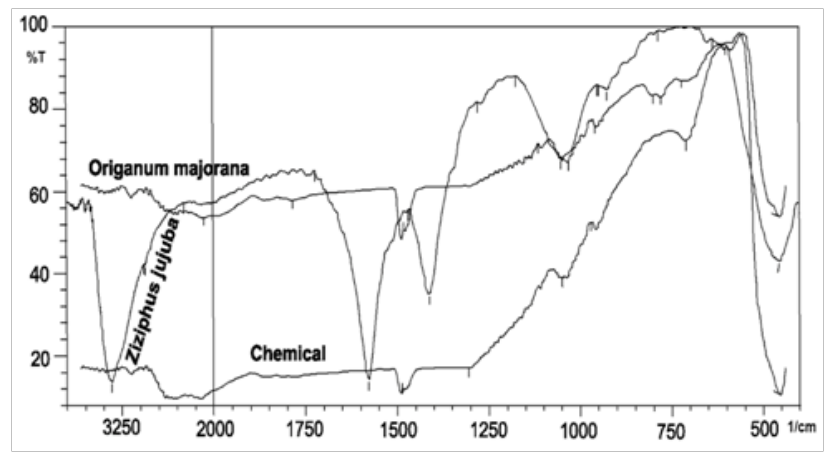

Figure 2 (A) FT-IR spectra of $\mathrm{ZnO}-\mathrm{NPs}$ by Origanum majorana leaves, Ziziphus jujube leaves and chemical.

In Figure 2A the peaks at 3386, 2360, 2017, 1519, 1369, 914 and $424 \mathrm{~cm}^{-1}$ for chemical method. The peaks by chemical method at $3386 \mathrm{~cm}^{-1}$ indicates the presence of $-\mathrm{OH}$ residue, probably because of humidity. Bands centered at 1519 and $1369 \mathrm{~cm}^{-1}$ corresponds to the group $\mathrm{C}=\mathrm{O}$ and $(\mathrm{C}-\mathrm{O}+\mathrm{C}-\mathrm{C})$ stretching, respectively. The band at $914 \mathrm{~cm}^{-1}$ may be related to $\mathrm{CO}_{2}^{-2}$ deformation mode. The band at $424 \mathrm{~cm}^{-1}$ indicates the presence of $\mathrm{ZnO}-\mathrm{NPs}$. It clearly shows the involvement of $-\mathrm{OH}$ and $\mathrm{C}=\mathrm{O}$ in the $\mathrm{ZnO}-\mathrm{NPs}$ synthesis. Figure $2 \mathrm{~B}$ the absorption peaks in green method using Elaeagnus angustifolia were at 3370, 2059, 1750,1608, 1490,1400, 1200, 1164, 900, 871, 700 and $555 \mathrm{~cm}^{-1}$, Cucumbers were at 3356, 2882, 2301, 1779, 1495, $1424,1255,1166,1093,952,797$ and $471 \mathrm{~cm}^{-1}$ and Pomegranate were at $3523,3001,2367,1401,1390,1120,806,444 \mathrm{~cm}^{-1}$. In the spectrum of Elaeagnus angustifolia the wide band at $3370 \mathrm{~cm}^{-1}$ corresponds to the stretching vibrations of $-\mathrm{OH}$. The weak absorption at 2059 is due to $\mathrm{C} \equiv \mathrm{C}$ stretching vibration. The peaks at 1608 and $1750 \mathrm{~cm}^{-1}$ are affiliated to the amide I, II. Absorption in 1400 and $1490 \mathrm{~cm}^{-1}$ mostly refers to an aromatic ring. The peak at $1200 \mathrm{~cm}^{-1}$ is depended on $\mathrm{C}-\mathrm{N}$ stretching as well as the peak at $1164 \mathrm{~cm}^{-1}$ which shows stretching absorption peak of C-O. The schema of absorption at $500-1000 \mathrm{~cm}^{-1}$ are related to the different modes of $\mathrm{CO}_{2}^{-2}$. Absorption peak at 555 $\mathrm{cm}^{-1}$ indicates the presence of $\mathrm{ZnO}$ nanoparticles. In the spectrum of Cucumbers absorption bands at 3356, 2882 and $2301 \mathrm{~cm}^{-1}$ are related to $\mathrm{OH}$ stretching vibrations, $-\mathrm{CH}$ stretching and N-H stretching, respectively. Absorption peaks at 1424 and $1495 \mathrm{~cm}^{-1}$ are affiliated to aromatic ring. The peaks at $1779,1255,1166$ and $1093 \mathrm{~cm}^{-1}$ are related to amide I, C-N stretching, stretching absorption peak of $\mathrm{C}-\mathrm{O}$, and stretching vibration $\mathrm{NH}-\mathrm{C}-\mathrm{O}$, respectively. Peak of $\mathrm{ZnO}$ is shown at $471 \mathrm{~cm}^{-1}$. The peak of Pomegranate absorption at 3523, 3001 and $2367 \mathrm{~cm}^{-1}$ are related to $\mathrm{OH}$ stretching vibrations, $-\mathrm{CH}$ stretching and $\mathrm{C}=\mathrm{O}$ stretching in the carboxyl, respectively. Absorption peak at 1390 
and $1401 \mathrm{~cm}^{-1}$ are related to $\mathrm{C}-\mathrm{N}$ stretching and amide II. The peaks at $1120 \mathrm{~cm}^{-1}$ are depended on $\mathrm{C}-\mathrm{O}$ and absorption peak of $\mathrm{ZnO}$ is at 444 $\mathrm{cm}^{-1}$. Some peaks showed shifts, may be due to the groups implication in the process of zinc oxide nanoparticles synthesis. FTIR indicates that aqueous extracts because of phytoconstituents like amide and proteins as capping agent prevents aggregation of the nanoparticles. ${ }^{40}$

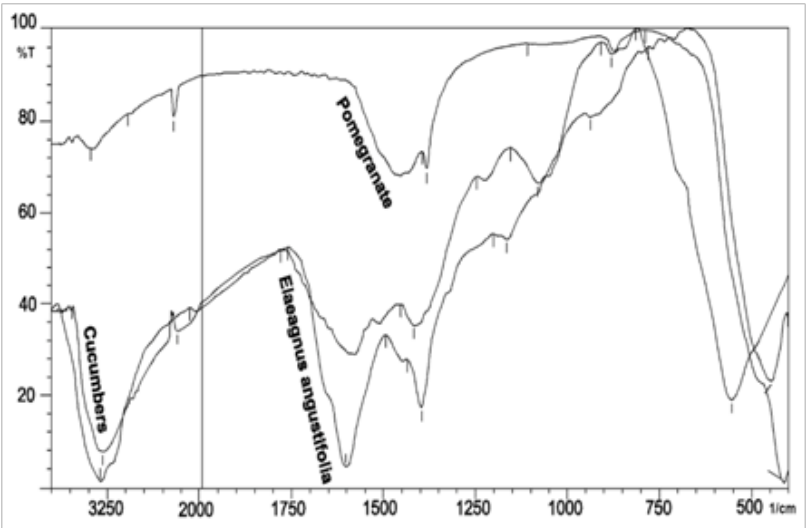

Figure 2 (B) FT-IR spectra of $\mathrm{ZnO}-\mathrm{NPs}$ by Elaeagnus angustifolia leaves, Pomegranate peel Cucumber fruit.

\section{UV-Vis absorption spectra}

Absorption spectroscopy is a powerful non-destructive method for using the optical properties of semiconducting nanoparticles applicable. The UV-Vis absorption spectra are a function of wavelength and the size of nanoparticles are dependent on $\lambda$.

Energy difference between the valence band and the conduction band is indicator of the $\mathrm{E}_{\mathrm{g}}$. There is a relationship between the absorption peak of $\mathrm{ZnO}-\mathrm{NPs}$ caused by SPR and their sizes. Based on this fact, more $\lambda_{\max }$ the more size of nanoparticles and less energy, leads to the red shift. The colloidal solution of $\mathrm{ZnO}$ in water was prepared by ultrasonic for $5 \mathrm{~min}$. Figure 3 presents the absorption spectra of $\mathrm{ZnO}-\mathrm{NPs}$ dispersed in water. It shows a strong absorption band at 372 $\mathrm{nm}$ with extract of Origanum majorana, a generic exciton absorption at $368 \mathrm{~nm}$ was observed for $Z$. jujuba aqueous extract and absorption peaks of $\mathrm{ZnO}$ at wavelength of Elaeagnus angustifolia, Cucumbers and Pomegranate are at 361, 378 and $381 \mathrm{~nm}$, respectively and 386 $\mathrm{nm}$ for chemical method.

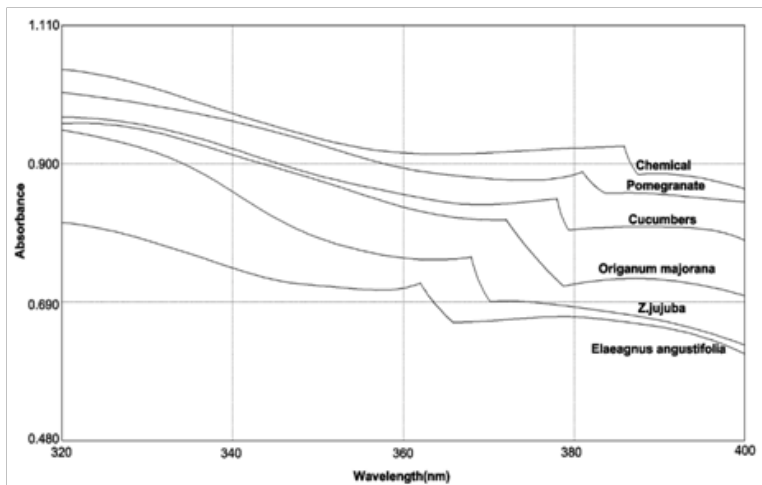

Figure 3 Absorption Spectra of $\mathrm{ZnO}-\mathrm{NPs}$ from green methods and chemical method.

\section{Optical properties}

The average particle size in a nano-colloid calculated from the absorption onset from UV-Vis absorption spectra by using an effective mass model.Optical energy gap can be calculated with equation (eq. 1) where, $E_{g}^{*}$ is the band gap energy $(e V), h$ is the Planck's constant $\left(6.626 \times 10^{-34} \mathrm{~J} . \mathrm{s}\right), \mathrm{C}$ is the light velocity $\left(3 \times 10^{8} \mathrm{~m} / \mathrm{s}\right)$, and $\lambda_{g}$ is the wavelength $(\mathrm{nm}): 41$

$$
E_{g}^{*}=h v \quad h c \frac{h c}{l_{g}}
$$

The dependence of particle size on the optical absorption energy can be shown based on an effective mass approximation according to the theoretical expression from Brus equation (eq. 2): ${ }^{42}$

$$
E_{g}^{*}=E_{g}^{b u l k}+\frac{h^{2} \pi^{2}}{2 r^{2}}\left[\frac{1}{m_{e}^{*}}+\frac{1}{m_{h}^{*}}\right]-\frac{1.8 e^{2}}{4 \pi \varepsilon \varepsilon_{0} r}-\frac{0.124 e^{4}}{h^{2}\left(4 \pi \varepsilon \varepsilon_{0}\right)^{2}}\left[\frac{1}{m_{e}^{*}}+\frac{1}{m_{h}^{*}}\right]^{-1}
$$

Size of individual nanoparticles in the lattice of the crystals could be determined by the Brus equation. Where, $\mathrm{E}_{\mathrm{g}}^{\text {bulk }}$ is the bulk band gap $(\mathrm{eV}), \mathrm{h}$ is the Planck's constant divided by $2 \pi, \mathrm{r}$ is the particle radius, $m_{e}$ is the electron effective mass, $m_{o}$ is the free electron mass, $e$ is the charge on the electron, $\varepsilon$ is the relative permittivity, $\varepsilon_{0}$ is the permittivity of free space, $m_{e}^{*}$ effective mass of a conduction band electron in $\mathrm{ZnO}$ and $\mathrm{m}_{\mathrm{h}}^{*}$ effective mass of a valence band hole in $\mathrm{ZnO}$. Generally, it is accepted in $\mathrm{ZnO} \mathrm{h}=6.625 \times 10^{-34} \mathrm{~J} . \mathrm{s}, \mathrm{m}_{\mathrm{e}}=$ $9.11 \times 10^{(-31)} \mathrm{kg}, m_{e}{ }_{e},=0.29 m_{e},=m_{h}^{*} 1.21, m_{e}=1.602 \times 10^{-19} \mathrm{C}, \varepsilon_{\mathrm{o}}$ $=8.854 \times 10^{-12} \mathrm{C}^{2} \cdot N^{-1} \cdot m^{-2}, \varepsilon=5.7$.

The comparison between the absorption peak of chemical and green methods (Figure 3), indicates a blue shift from $386 \mathrm{~nm}$ to 361 $\mathrm{nm}$ when the size of nanoparticle reduces. It has agreement with the Mie theory predicted when the size of nanoparticles decrease, a blue shift of SPR peak position would be seen. ${ }^{43}$ Table 1 shows particle size determination from UV-Vis absorption spectra.

Table I The nano $\mathrm{ZnO}$ particle sizes obtained from UV-Vis absorption Spectra data

\begin{tabular}{lll}
\hline Methods & $\lambda_{\max }$ & 2r (nm) \\
\hline Elaeagnus angustifolia & $36 \mathrm{I}$ & 4.7 \\
Z. jujuba & 368 & 5.3 \\
Origanum majorana & 372 & 5.7 \\
Cucumbers & 378 & 6.7 \\
Pomegranate & $38 \mathrm{I}$ & 7.4 \\
Chemical & 386 & 11.9 \\
\hline
\end{tabular}

\section{XRD analysis}

We chose three $\mathrm{ZnO}$ samples were synthesized through the different green methods and the sample synthesized by chemical method for size calculated through X-ray diffraction. Figures 4 
(A-D) shows XRD pattern of $\mathrm{ZnO}-\mathrm{NPs}$ synthesized by zinc acetate dehydrate and sodium hydroxide in the presence of aqueous extract. The XRD pattern showed the orientation and crystal nature of zinc oxide nanoparticles. NPs synthesized by Elaeagnus angustifolia in Figure 4A show distinctive peaks at (100), (002), (101), (102), (110), (103), (200), (112) and (201). For nanoparticles synthesized by $Z$. jujuba leaves extract at room temperature, in Fig $4 \mathrm{~b}$ the peak position with $2 \theta$ values of $31.22^{\circ}, 33.9^{\circ}, 35.76^{\circ}, 47.16^{\circ}, 56.34^{\circ}, 62.42^{\circ}$, $66.50^{\circ}, 67.56^{\circ}, 69.16^{\circ}$, and $76.9^{\circ}$ and the nanoparticles synthesis with Origanum majorana in Fig $4 \mathrm{c}$ peak position with $2 \theta$ values of $31.4^{\circ}$, $34.6^{\circ}, 35.9^{\circ}, 47.2^{\circ}, 56.3^{\circ}, 62.5^{\circ}, 65.9^{\circ}, 67.7^{\circ}, 68.6^{\circ}$, and $77.4^{\circ}$ and nanoparticles synthesis by Cucumber extract in Fig $4 \mathrm{~d}$ with $2 \theta$ values of $31.7^{\circ}, 34.3^{\circ}, 36.2^{\circ}, 47.5^{\circ}, 56.6^{\circ}, 62.9^{\circ}, 66.4^{\circ}, 67.9^{\circ}, 69.1^{\circ}$, and $77.0^{\circ}$ and $2 \theta$ values at $31.8^{\circ}, 34.4^{\circ}, 36.2^{\circ}, 47.5^{\circ}, 56.7^{\circ}, 62.9^{\circ}, 66.5^{\circ}$, $68.0^{\circ}, 69.1^{\circ}$ and $75.6^{\circ}$ corresponding to (100), (002), (101), (102), (110), (103), (200), (112), (201), and (202) for chemical method in Figure 4E which are in agreement with hexagonal $\mathrm{ZnO}$ (Reference code: 01-079-2205). XRD is a method to measure the average crystal size of a compound. XRD peak broadening increases with the crystal size decrease because of the full width at half maximum (FWHM) increase. The average particle size (D) of synthesized nanoparticles was calculated by the well-known Debye-Scherrer's equation $3:^{33}$

$$
D=\frac{k \lambda}{\beta \operatorname{Cos} \theta}
$$

$\mathrm{K}=0.89, \lambda$ the $\mathrm{X}$-ray wavelength of $\mathrm{X}$-ray source $\left(\mathrm{CuK}_{\alpha}\right.$ line $-0.1541 \mathrm{~nm}), \beta$ is FWHM and $\theta$ is Bragg's diffraction angle. Size of nanoparticles for Elaeagnus angustifolia is $14 \mathrm{~nm}$, Ziziphus jujube is $17 \mathrm{~nm}$, Origanum majorana is $19 \mathrm{~nm}$, cucumber is $20 \mathrm{~nm}$ and chemical method is $26 \mathrm{~nm}$.

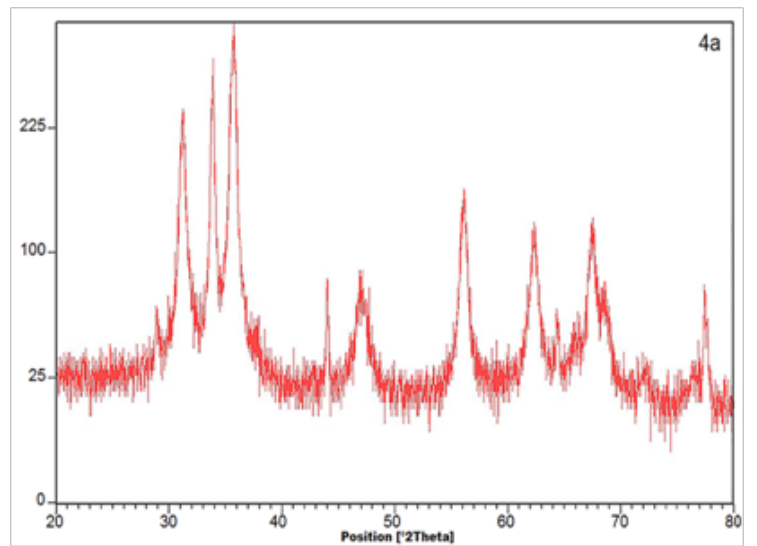

Figure 4 (A) XRD spectra of ZnO-NPs using green methods; Elaeagnus angustifolia leaves.

\section{SEM analysis}

Size of nanoparticles gained from Elaeagnus angustifolia sample is smaller than other synthesis by extracts, so we selected this nanoparticle to checked morphologies of $\mathrm{ZnO}-\mathrm{NPs}$. Figures 5 shows the SEM image of ZnO-NPs at magnification less than 2000. The aqueous extract of Elaeagnus angustifolia strongly influences morphologies of $\mathrm{ZnO}-\mathrm{NPs}$. Figure 5 shows the main morphology of nanoparticles are nearly spherical with diameter about $30 \mathrm{~nm}$. The morphology of $\mathrm{ZnO}-\mathrm{NPs}$ prepared by chemical method is presented in Figures $6(\mathrm{E}-\mathrm{H})$. Size of nanoparticles synthesized by chemical method varies were about $40 \mathrm{~nm}$.

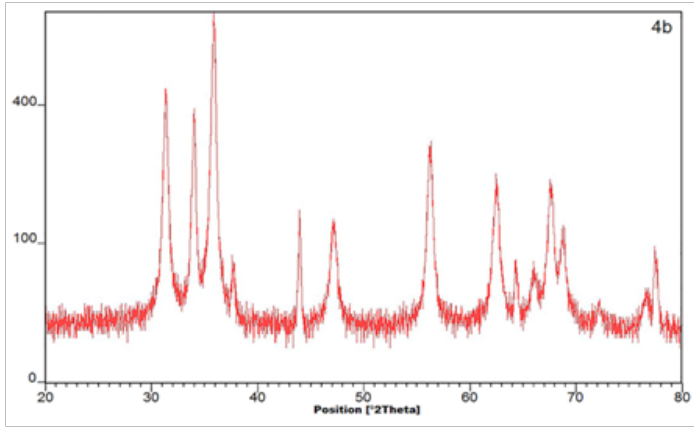

Figure 4 (B) XRD spectra of ZnO-NPs using green methods; Ziziphus jujube leaves.

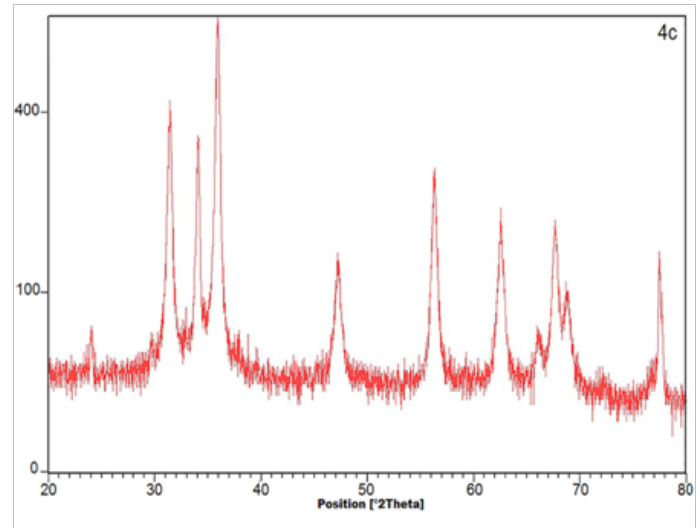

Figure 4 (C) XRD spectra of ZnO-NPs using green methods; Origanum majorana leaves.

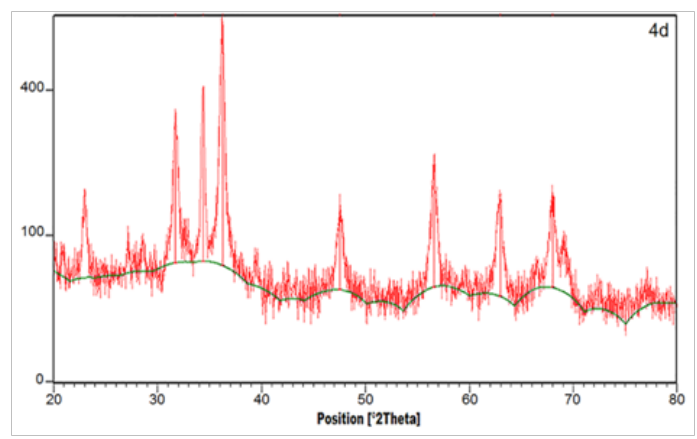

Figure 4 (D) XRD spectra of $\mathrm{ZnO}-\mathrm{NPs}$ using green methods; Origanum majorana leaves Cucumber fruit.

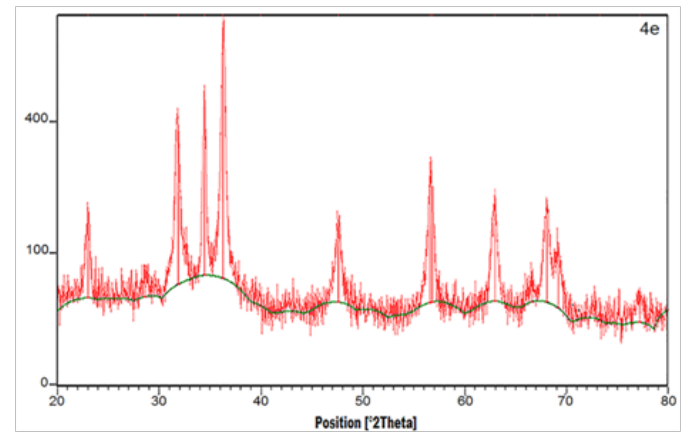

Figure 4 (E) XRD spectra of ZnO-NPs using green methods: chemical method. 

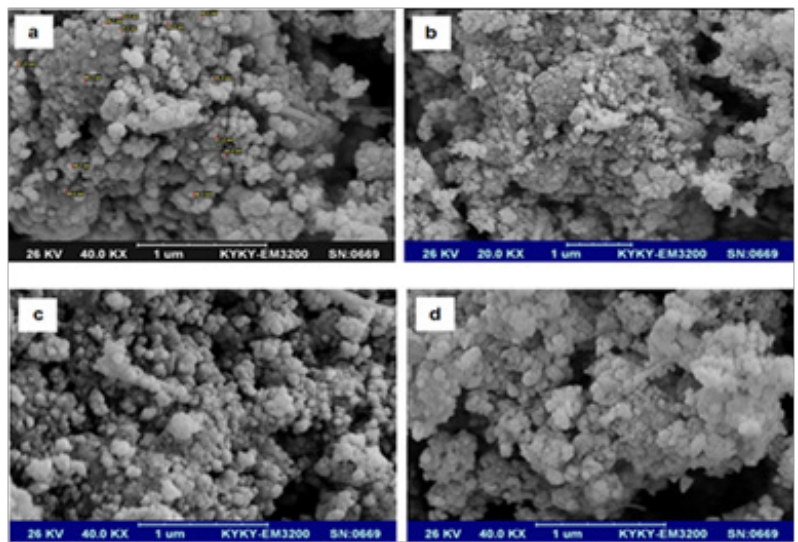

Figure 5 SEM pictures of $\mathrm{ZnO}-\mathrm{NPs}$ synthesized by aqueous extract of Elaeagnus angustifolia.
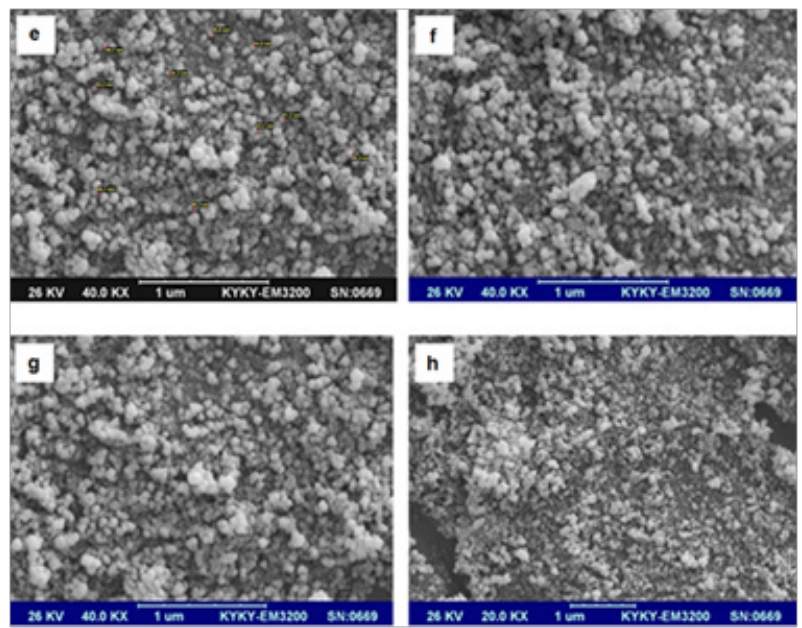

Figure 6 SEM images of synthesized ZnO-NPs using chemical method.

\section{Conclusion}

According to our results and comparison, the size of nanoparticles gained by green method were smaller than the ones gained by chemical method. Green synthesis of $\mathrm{ZnO}-\mathrm{NPs}$ using extracs plant yielded nano-sized $\mathrm{ZnO}$ through a simple and fast reaction. FTIR analysis aqueous showed the presence of phytoconstituents such as amide which are surface active molecules, responsible for stabilization and reduction size of $\mathrm{ZnO}-\mathrm{NPs}$. In this work, we compared size of nanoparticles obtained by XRD, SEM and UV-Vis spectra. The data gained by XRD shows the crystal size and the data of SEM gives the nanoparticle size. Therefore, XRD data is a little smaller than SEM data. Both sizes from XRD and SEM are same when there is a single crystal. There was a major difference between the size obtained by Brus equation and the size gained by XRD and SEM which was probably because of solvation of the nanoparticles with water and also because Brus equation measures the size of individual particles in the crystal lattice. So single particles were smaller than the nanocrystals and nanoparticles gained form XRD or SEM. Therefore, the size calculated using the Brus equation is closer to values obtained from XRD and SEM when the size of particles decreases to quantum dots.
There is the relationship between the optical absorption spectrum of nanoparticles caused by surface plasmon absorption and their sizes. Such absorption spectra can be analyzed using Brus equation. The synthesized $\mathrm{ZnO}$ nanoparticles exhibit sharp UV band corresponding to near band gap excitonic emission and broad emission band due to the oxygen vacancy. It is believed that, we should try this method out, as we can recover the sample. This method should give average sizes of $\mathrm{ZnO}$ nanoparticles, irrespective of the shapes of the crystal lattice. We may compare sizes at different conditions and get an idea of the variation, and infer from that.

\section{Acknowledgments}

The authors wish to thanks Payame Noor University for supporting of this research.

\section{Conflicts of interest}

None.

\section{References}

1. Sangeetha G, Rajeshwari S, Venckatesh R. Green synthesis of zinc oxide nanoparticles by aloe barbadensis miller leaf extract: Structure and optical properties. Mater Res Bull. 2011;46:2560-2566.

2. Mochinaga R, Yamasaki T, Arakawa T. The gas sensing of SmCoOX/ MOX $(\mathrm{M}=\mathrm{Fe}, \mathrm{Zn}, \mathrm{In}, \mathrm{Sn})$ having a heterojunction. Actuat B: Chem. 1998;52:96-99.

3. Gao PX, Ding Y, Mai W, et al. Conversion of Zinc Oxide Nanobelts into Superlattice-Structured Nanohelices. Science. 2005;309:1700-1704.

4. Elseviers WF, Verelst H. Transition metal oxides for hot gas desulphurization. Fuel. 1999;78(5):601-612.

5. Siyanbola TO, Sasidhar K, Anjaneyulu B, et al. Anti-microbial and anticorrosive poly (ester amide urethane) siloxane modified $\mathrm{ZnO}$ hybrid coatings from Thevetia peruviana seed oil. Mater Sci. 2013;48(23):82158227.

6. Shinobu Fujihara, Hiroki Naito, Toshio Kimura. Visible photoluminescence of $\mathrm{ZnO}$ nanoparticles dispersed in highly transparent $\mathrm{MgF}_{2}$ thin-films via sol-gel process. Thin Solid Film. 2001;389:227-232.

7. Bisht G, Rayamajhi S. ZnO Nanoparticles: A Promising Anticancer Agent. Nanobiomed. 2016;1:31-11.

8. Zhang Y, Nayak TR, Hong H, et al. Biomedical Applications of Zinc Oxide Nanomaterials. Curr Mol Med. 2013;13(10):1633-1645.

9. Koh YW, Lin M, Tan CK, et al. Self-Assembly and Selected Area Growth of Zinc Oxide Nanorods on Any Surface Promoted by an Aluminum Precoat. J Phys Chem B. 2004;108 (31):11419-11425.

10. Sharma D, Sharma S, Kaith BS, et al. Synthesis of $\mathrm{ZnO}$ nanoparticles using surfactant free in-air and microwave method. Appl Surf Sci. 2011;257: 9661-9672.

11. Wang J, Gao L. Inorganic Chemistry Communications. In Org Chem. 2003;6:877-881.

12. Kaneko D, Shouji H, Kawai T. Synthesis of $\mathrm{ZnO}$ Particles by AmmoniaCatalyzed Hydrolysis of Zinc Dibutoxide in Nonionic Reversed Micelles. Langmuir. 2000;16(9):4086-4089.

13. Sato T, Tanigaki T, Suzuki H, et al. Structure and optical spectrum of $\mathrm{ZnO}$ nanoparticles produced in RF plasma. J Cryst Growth. 2003;255:313316. 
14. Makarov VV, Love AJ, Sinitsyna OV, et al. Green Nanotechnologies: Synthesis of Metal Nanoparticles Using Plants. Acta Naturae. 2014;6(1):35-44.

15. Brewer MS. Natural Antioxidants: Sources, Compounds, Mechanisms of Action, and Potential Applications. Food Sci Food safety. 2011;10(4):221-247.

16. Roby MHH, Sarhan MA, Selima KAH, et al. Evaluation of antioxidan activity, total phenols and phenolic compounds in thyme (Thymus vulgaris L.), sage (Salvia officinalis L.), and marjoram (Origanum majorana L.) extracts. Ind Crop Prod. 2013;43(2):827-831.

17. Dipti N Deshmane, Chhaya H Gadgoli, Ganesh V Halade. Anticonvulsan effect of Origanum majorana L. Pharmacologyonline. 2007;1:64-78.

18. el-Ashmawy IM, el-Nahas AF, Salama OM. Protective Effect of Volatile Oil, Alcoholic and Aqueous Extracts of Origanum majorana on Lead Acetate Toxicity in Mice. Basic Clin Pharmacol Toxicol. 2005;97(4) $238-243$.

19. Zaidi SF, Yamada K, Kadowaki M, et al. Bactericidal activity of medicinal plants, employed for the treatment of gastrointestinal ailments, against Helicobacter pylori. J Ethnopharmacol. 2009;121(2):286-291.

20. Chung YK, Heo HJ, Kim EK, et al. Inhibitory effect of ursolic acid purified from Origanum majorana L. on the acetylcholinesterase. Mol Cells. 2001;11(2):137-143.

21. Meiselman HL, Halpern BP, Dateo GP. Reduction of sweetness judgements by extracts from the leaves of Zjujuba. Physiol Behav. $1975 ; 17: 313-317$

22. Guo S, Duan JA, Tang YP, et al. Triterpenoid acids from Ziziphus jujube. Chem Nat Compd. 2011;47:138-139.

23. Klich MG. Leaf variations in Elaeagnus angustifolia related to environmental heterogeneity. Environmental and Experimental Botan. 2000;44(3):171-183.

24. Wang Y, Guo T, Li JY, et al. Four flavonoid glycosides from the pulps of Elaeagnus angustifolia and their antioxidant activities. Adv Mat Res. 2012;756:16-20.

25. Ghasemi Pirbalouti A, Momeni M, Bahmani M. Ethnobotanical study of medicinal plants used by Kurd tribe in Dehloran and Abdanan districts, Ilam province, Iran. Afr J Tradit Complement Altern Med. 2013;10(2):368-385

26. Awan MR, Jamal Z, Khan A. Ethno-botanical studies of economically important plants from mountainous region of Gilgit-Baltistan, Pakistan. Science Technology and Development. 2013;32:308-318.

27. Khan N, Ahmed M, Ahmed A, et al. Important medicinal plants of Chitra Gol National Park (CGNP) Pakistan. Pak J Bot. 2011;43(2):797-809.

28. Ali H, Qaiser M. The ethnobotany of Chitral valley, Pakistan with particular reference to medicinal plants. Pak J bot. 2009;41(4):20092041.
29. Qureshi RA, Ghufran MA, Sultana KN, et al. Ethnobotanical studies of medicinal plants of Gilgit District and surrounding areas. Ethnobotany Research and Applications. 2006;5:115-122.

30. Farzaei MH, Bahramsoltani R, Abbasabadi Z, et al. A comprehensive review on phytochemical and pharmacological aspects of Elaeagnus angustifolia L. J Pharm Pharmacol. 2015;67(11):1467-480.

31. Naveed Akhtar, Arshad Mehmood, Barkat Ali Khan, et al. Exploring cucumber extract for skin rejuvenation. Afr J Biotechnol. 2011;10:12061216.

32. Aslam MN, Lansky EP, Varani J. Pomegranate as a cosmeceutical source: Pomegranate fractions promote proliferation and procollagen synthesis and inhibit matrix metalloproteinase-1 production in human skin cells. $J$ Ethnopharmacol. 2006;103(3):311-318.

33. Ramesh M, Anbuvannan M, Viruthagiri G. Green synthesis of $\mathrm{ZnO}$ nanoparticles using Solanum nigrum leaf extract and their antibacterial activity. Spectrochim Acta A: Mol Biomol Spectrosc. 2015;136:864-870.

34. Gnanasangeetha D, Sarala. One Pot Synthesis of Zinc Oxide Nanoparticles via Chemical and Green Method. Res J Mat Sci. 2013;1:1-8.

35. Saleh R, Djaja NF, Prakoso SP. The correlation between magnetic and structural properties of nanocrystalline transition metal-doped $\mathrm{ZnO}$ particles prepared by the co-precipitation method. J Alloy Compd. 2013;546:48-56.

36. Sathyavathi R, Krishna MR, Rao SV, et al. Biosynthesis of Silver Nanoparticles Using Coriandrum Sativum Leaf Extract and Their Application in Nonlinear Optics. Adv Sci Lett. 2010;3:138-143.

37. Shankar SS, Ahmad A, Sastry M. Geranium Leaf Assisted Biosynthesis of Silver Nanoparticles. Biotechnol Prog. 2003;19:1627-1631.

38. Bhuiyan MNI, Begum J, Sultana M. Chemical composition of leaf and seed essential oil of Coriandrum sativum L. from Bangladesh, Bangl. $J$ Pharmacol. 2009;4:150-153.

39. Marimuthu T, Anandhan N, Ravi G, et al. Structural, Functional and Optical Studies on Ce Doped ZnO Nanoparticles. J Nanosci Nanotechnol. 2014;2:62-65

40. Abrishami ME, Hosseini SM, Kakhki A, et al. Synthesis and Structure of Pure and Mn-doped Zinc Oxide nanopowders. Int J Nanosci. 2010;9:19_ 28 .

41. Masuda Y, Yamagishi M, Seo WS, et al. Photoluminescence from $\mathrm{ZnO}$ Nanoparticles Embedded in an Amorphous Matrix. Cryst Growth Des. 2008;8:1503-1508.

42. Brus LE. Electron-electron and electron-hole interactions in small semiconductor crystallites: The size dependence of the lowest excited electronic state. J Chem Phys. 1984;80:4403-4409.

43. Smitha SL, Nissamudeen KM, Philip D, et al. Studies on surface plasmon resonance and photoluminescence of silver nanoparticles. Spectrochim Acta A: Mol Biomol Spectrosc. 2008;71:186-190. 